\title{
Selected Thermodynamic Parameters of Antioxidant Activity of Coumarin Based Heterocyclic Compounds ${ }^{\dagger}$
}

\author{
Ana Amić * and Elena Gotal
}

Citation: Amić, A.; Gotal, E. Selected Thermodynamic Parameters of Antioxidant Activity of Coumarin Based Heterocyclic Compounds.

Chem. Proc. 2021, 3, 109.

https://doi.org/10.3390/ ecsoc-24-08385

Academic Editors: Julio A. Seijas and M. Pilar Vázquez-Tato

Published: 14 November 2020

Publisher's Note: MDPI stays neutral with regard to jurisdictional claims in published maps and institutional affiliations.

Copyright: $\odot 2020$ by the authors. Licensee MDPI, Basel, Switzerland. This article is an open access article distributed under the terms and conditions of the Creative Commons Attribution (CC BY) license (http://creativecommons.org/licenses/by/4.0/).
Department of Chemistry, Josip Juraj Strossmayer University of Osijek, Ulica cara Hadrijana 8A, 31000 Osijek, Croatia; gotal551@icloud.com

* Correspondence: aamic@kemija.unios.hr

+ Presented at the 24th International Electronic Conference on Synthetic Organic Chemistry, 15 November-15 December 2020; Available online: https://ecsoc-24.sciforum.net/.

\begin{abstract}
Coumarin and coumarin derivatives are bioactive compounds that have an important role in medicinal chemistry, for example in the development of anti-inflammatory, anticancer and antiviral drugs. These compounds are also very powerful antioxidants that successfully scavenge free radicals and prevent or alleviate oxidative stress. The antioxidant potential of selected heterocyclic compounds containing coumarin core was investigated theoretically, the focus of this study was on hydrogen atom transfer mechanism (HAT) and single electron transfer followed by a proton transfer mechanism (SET-PT). Using MOPAC2012 PM7, reaction enthalpies related to the cleavage of O$\mathrm{H}, \mathrm{N}-\mathrm{H}$ and $\mathrm{C}-\mathrm{H}$ bonds via selected mechanisms of free radical scavenging were studied and calculated. The effect of the position of the hydroxyl group, as well as other functional groups, on the antioxidant activity, was examined. Based on obtained results, Schiff bases, thiosemicarbazides, oxadiazoles and 4-thiazolidinones containing one or more $\mathrm{OH}$ - groups exhibit higher radical scavenging properties.
\end{abstract}

Keywords: coumarin; antioxidants; PM7; HAT; SET-PT

\section{Introduction}

Coumarin and coumarin compounds are a group of phenolic compounds that was first isolated from the beans of the Tonka plant, Dipteryx odorata (Aubl.) Wild, in 1820. These heterocyclic compounds containing oxygen are widely distributed in the plant kingdom, where some are present in free form while others are present in the form of glycosides, e.g., bound with carbohydrate (for example glucose). These phytochemicals can be described as colorless crystalline compounds soluble in organic solvents [1,2]. Hundreds have been isolated from plants, the most widespread being umbelliferon, esculetin and scopoletin. Some plant species, such as dates, strawberries, apricots, cherries and cinnamon contain a very high amount of these compounds [3-7].

Due to their relatively simple structure, coumarins and their derivatives have various uses, for example in the perfume industry (due to the unique and intense scent similar to vanilla), as tobacco aroma enhancers, in some alcoholic beverages [8], in insecticides, as additives in soaps and toothpaste, as sweeteners, as additives to rubber and plastic materials, in aerosols, etc. [7,9]. Additionally, the bioactivity of these compounds is especially diverse-coumarin and coumarin derivatives have shown anticancer, antitumor, antibacterial, antifungal and anti-inflammatory activity, some may inhibit the activity of some enzymes and reduce the concentration of triglycerides in the blood. Hydroxycoumarins are very powerful antioxidants and have the ability to eliminate excess free radicals and reduce oxidative stress. Free radicals are constantly produced in our body for metabolic purposes, but we are exposed to various additional sources of free radicals as well (ioniz- 
ing radiation, UV light, pollution, etc.). Excess free radicals may attack biological macromolecules giving rise to membrane and DNA damage, and protein modifications [10]. This type of oxidative damage may be involved in the pathogenesis of various chronic diseases, so to fight oxidative stress various exogenous antioxidants may be of use. In this way, some coumarin derivatives may play an important role in the prevention of chronic and age-related diseases such as neurodegenerative and cardiovascular diseases [4].

\section{Methods}

MOPAC2012 2 is a semi-empirical quantum-chemical program based on Dewar and Thiel NDDO approximation. In this paper, it was used to calculate reaction enthalpies of selected compounds with coumarin core in the gas phase in order to study the thermodynamics of $\mathrm{O}-\mathrm{H}, \mathrm{N}-\mathrm{H}$ and $\mathrm{C}-\mathrm{H}$ bond cleavage necessary for antioxidant activity. Though the application of other commercially available computational programs (such as Gaussian) may result in more accurate calculations of thermodynamic parameters, their disadvantage is their high price and long calculation time, depending on the computer, the complexity of the compound structure and computational details (level of theory, basis set, functional, solvation model, etc.). Thermodynamic calculations run via the PM7 method are less accurate, but are faster to obtain, and are similar to the results obtained via other computational programs. Hence MOPAC was used in this preliminary study, primarily because of very fast calculations and fast obtained results.

In this preliminary study, two mechanisms of antioxidant activity based on hydrogen atom abstraction were studied. Those mechanisms were hydrogen atom abstraction (HAT mechanism) and single electron transfer followed by proton transfer (SET-PT) mechanism. As can be seen in Equation (1), the HAT mechanism is characterized by the translocation of a hydrogen atom from the antioxidant molecule (A-OH) to the free radical ( $\mathrm{RO}$ ). This mechanism occurs in one step and is characterized by a thermodynamic parameter named bond dissociation enthalpy (BDE) [11].

$$
\mathrm{A}-\mathrm{OH}+\mathrm{RO}^{\circ} \rightarrow \mathrm{A}-\mathrm{O}^{\circ}+\mathrm{ROH}
$$

In the HAT mechanism homolytic bond cleavage occurs, there is no charge separation, so it is preferred in the gas phase and non-polar medium. Equation (2) shows how BDE can be calculated:

$$
\mathrm{BDE}=H\left(\mathrm{~A}-\mathrm{O}^{\circ}\right)+H\left(\mathrm{H}^{\circ}\right)-H(\mathrm{~A}-\mathrm{OH})
$$

where $H\left(\mathrm{~A}-\mathrm{O}^{\circ}\right), H\left(\mathrm{H}^{*}\right)$ and $H(\mathrm{~A}-\mathrm{OH})$ are enthalpies of formation of antioxidant radical, transferred hydrogen atom, and antioxidant molecule. Lower $H_{\mathrm{BDE}}$ indicates a better ability of an antioxidant in donating a hydrogen atom to the free radical [11,12].

SET-PT mechanism occurs in two steps as shown in Equations (3) and (4). In the first step of this mechanism, electron transfer takes place and the neutral antioxidant molecule is modified into radical cation $\left(\mathrm{AOH}^{+}\right)$, while in the second step radical cation loses a proton and antioxidant radical is formed (AO) [11].

$$
\begin{aligned}
& \mathrm{A}-\mathrm{OH} \rightarrow \mathrm{A}-\mathrm{OH}^{++}+\mathrm{e}^{-} \\
& \mathrm{A}-\mathrm{OH}^{+} \rightarrow \mathrm{A}-\mathrm{O}^{\cdot}+\mathrm{H}^{+}
\end{aligned}
$$

In the case of SET-PT, heterolytic bond cleavage occurs, there is charge separation and this mechanism is preferred in the polar medium. This mechanism is characterized with thermodynamic parameters shown in Equations (5) and (6): 


$$
\begin{gathered}
\mathrm{IP}=H\left(\mathrm{~A}-\mathrm{O}^{\cdot+}\right)+H\left(\mathrm{e}^{-}\right)-H(\mathrm{~A}-\mathrm{OH}) \\
\mathrm{PDE}=H\left(\mathrm{~A}-\mathrm{O}^{\cdot}\right)+H\left(\mathrm{H}^{+}\right)-H\left(\mathrm{~A}-\mathrm{O}^{\cdot+}\right)
\end{gathered}
$$

Ionization potential, IP, is the energy necessary to release an electron and this value characterizes the first step of the SET-PT mechanism. It can be calculated by subtracting the sum of the enthalpy of formation of radical cation and enthalpy of formation of an electron from the enthalpy of formation of the antioxidant molecule. The second step, in which antioxidant radical is formed, is characterized by proton dissociation enthalpy, or PDE, and can be calculated by subtracting the enthalpy of formation of radical cation from the sum of the enthalpy of formation of antioxidant radical and proton $[11,13,14]$.

All above-mentioned mechanisms of antioxidant activity have the same productsneutralized radical and a stable antioxidant radical. Accordingly, thermodynamic balance is presented with Equation (7), in which can be seen that reaction enthalpy BDE matches the sum of reaction enthalpies IP and PDE [11]:

$$
\Delta_{\mathrm{r}} \mathrm{HBDE}=\Delta_{\mathrm{r}} \mathrm{HIP}+\Delta_{\mathrm{r}} \mathrm{HPDE}
$$

It is correct to say that there is a competitive relationship between these reactions and mechanisms, and there is also the possibility for these mechanisms to occur parallel [11].

\section{Results and Discussion}

Coumarins may reduce the production of free radicals in the organism and stimulate the scavenging of reactive oxygen species (ROS), meaning they may behave as antioxidants and act to diminish biological damage caused by oxidative stress. In order to determine the ability of compounds, namely phenolic antioxidants, to scavenge ROSs, O-H bond cleavage and potential to donate electron is studied. This implies the calculation of BDE and IP. Lower BDE and IP lead to better antioxidant activity. For example, Mohajeri et al. (2009) found that BDE values in the gas phase are in the range $69.9-104.0 \mathrm{kcal} / \mathrm{mol}$ for vitamins and 71.2-85.1 for phenolic acids. The authors also discovered that comparing BDE of vitamin $\mathrm{E}$ and $\mathrm{C}$, the reduction of heterocyclic ring enhances antioxidant activity. Determined IP values for vitamins and phenolic acids were in the range 167.38-205.59 $\mathrm{kcal} / \mathrm{mol}$, leading to the conclusion that both BDE and IP values were lower for phenolic acids than for vitamins, indicating phenolic acids as better antioxidants [15].

In this preliminary study, BDE and IP values for four groups of compounds with coumarin core were studied. Structures of compounds (1-51) and results of thermodynamic calculations of studied mechanisms of antioxidant activity are presented in Tables 1-3. Thermodynamic calculations refer to the gas phase.

Table 1. Structures of studied Schiff bases (compounds 1-26) and results of thermodynamic calculations $(\mathrm{kcal} / \mathrm{mol})$.

No. Structure




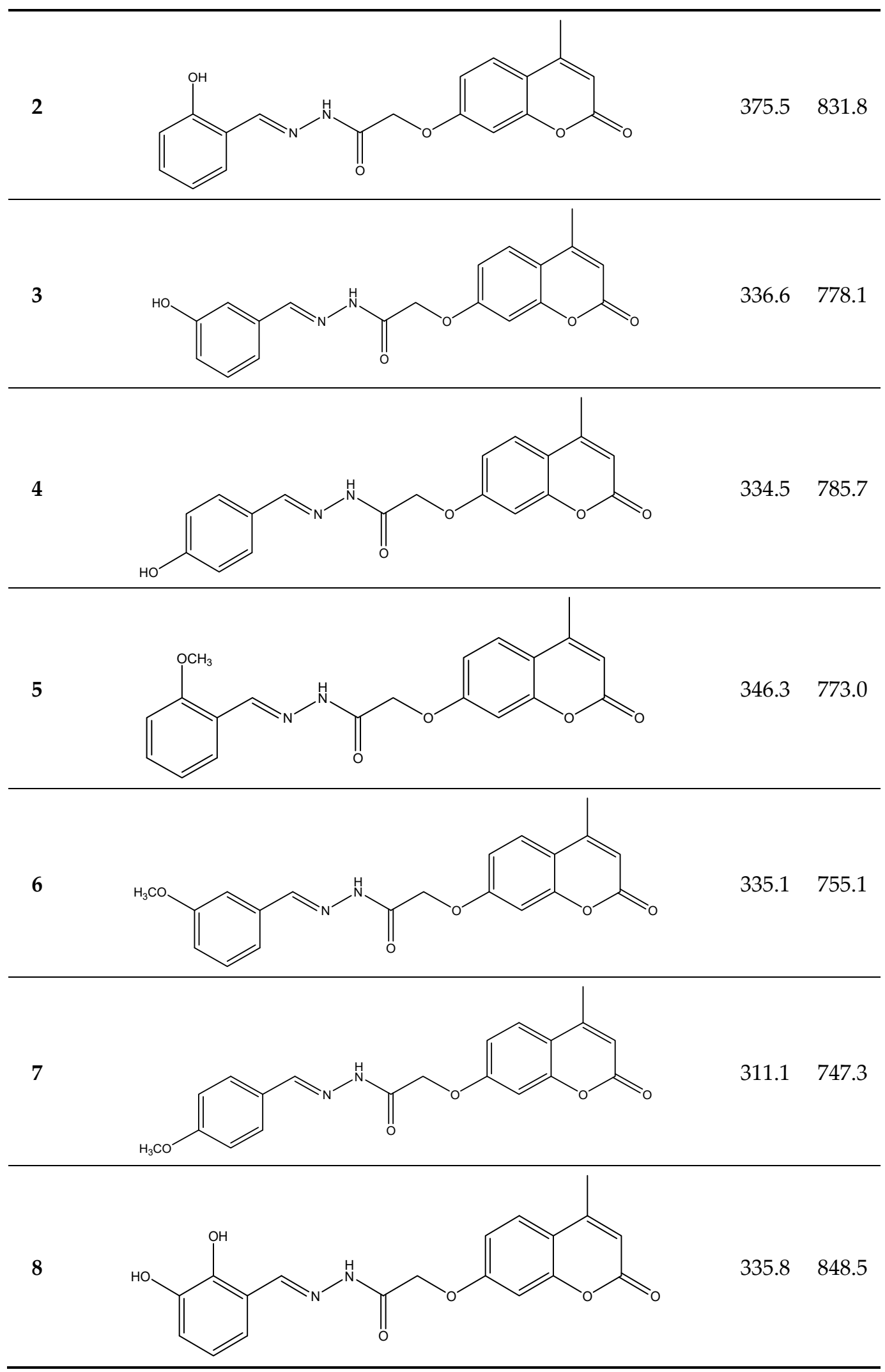




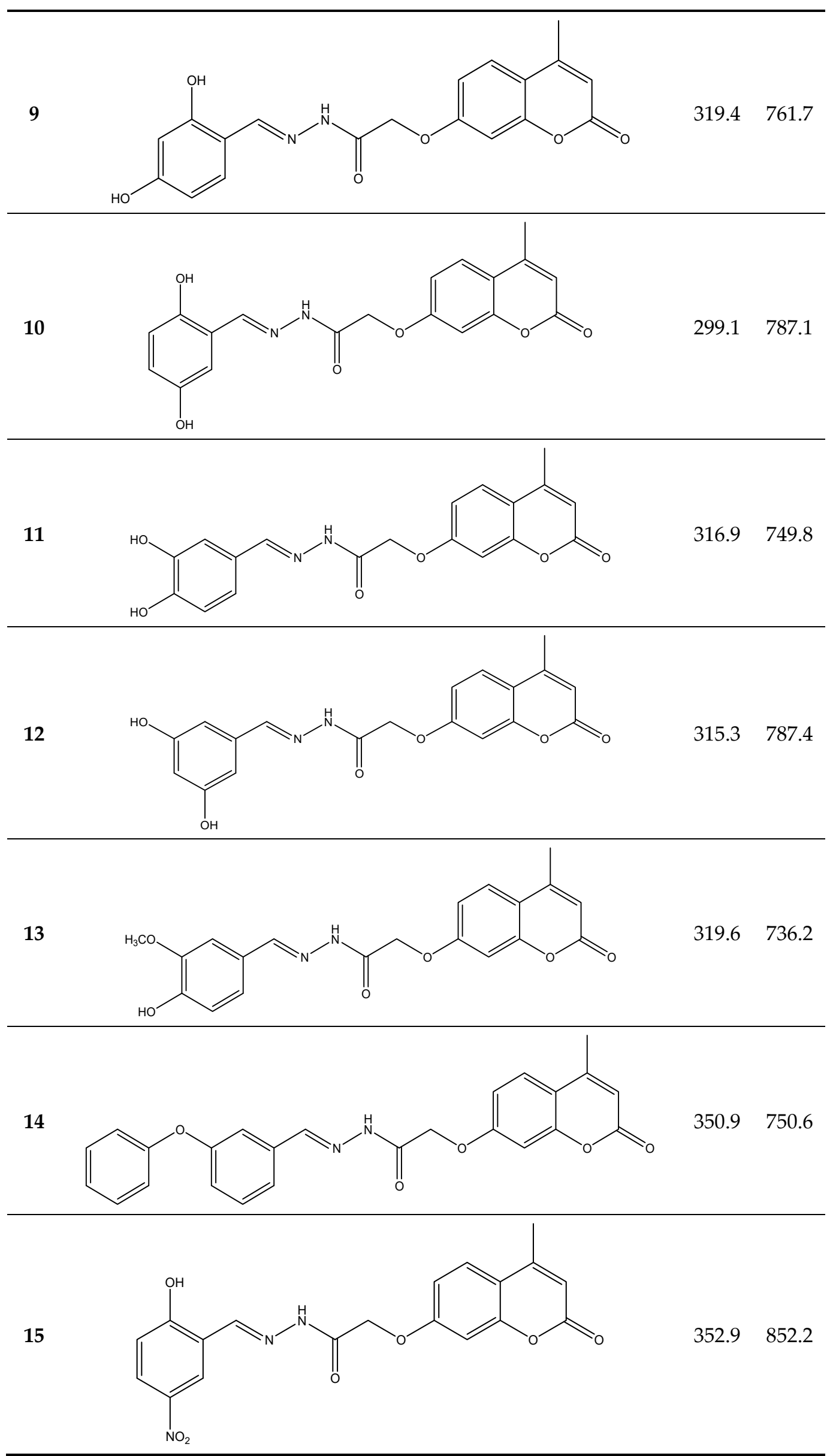




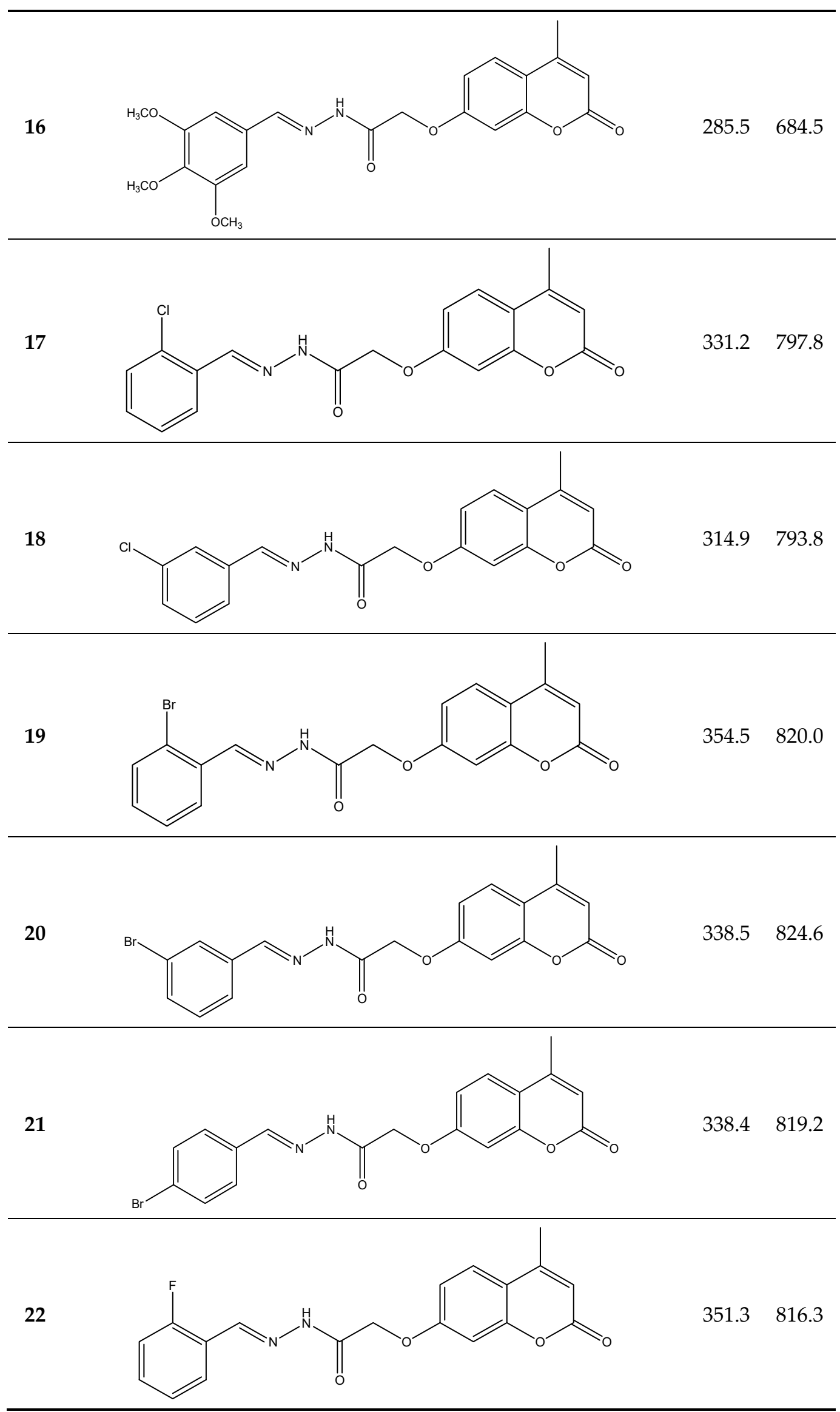




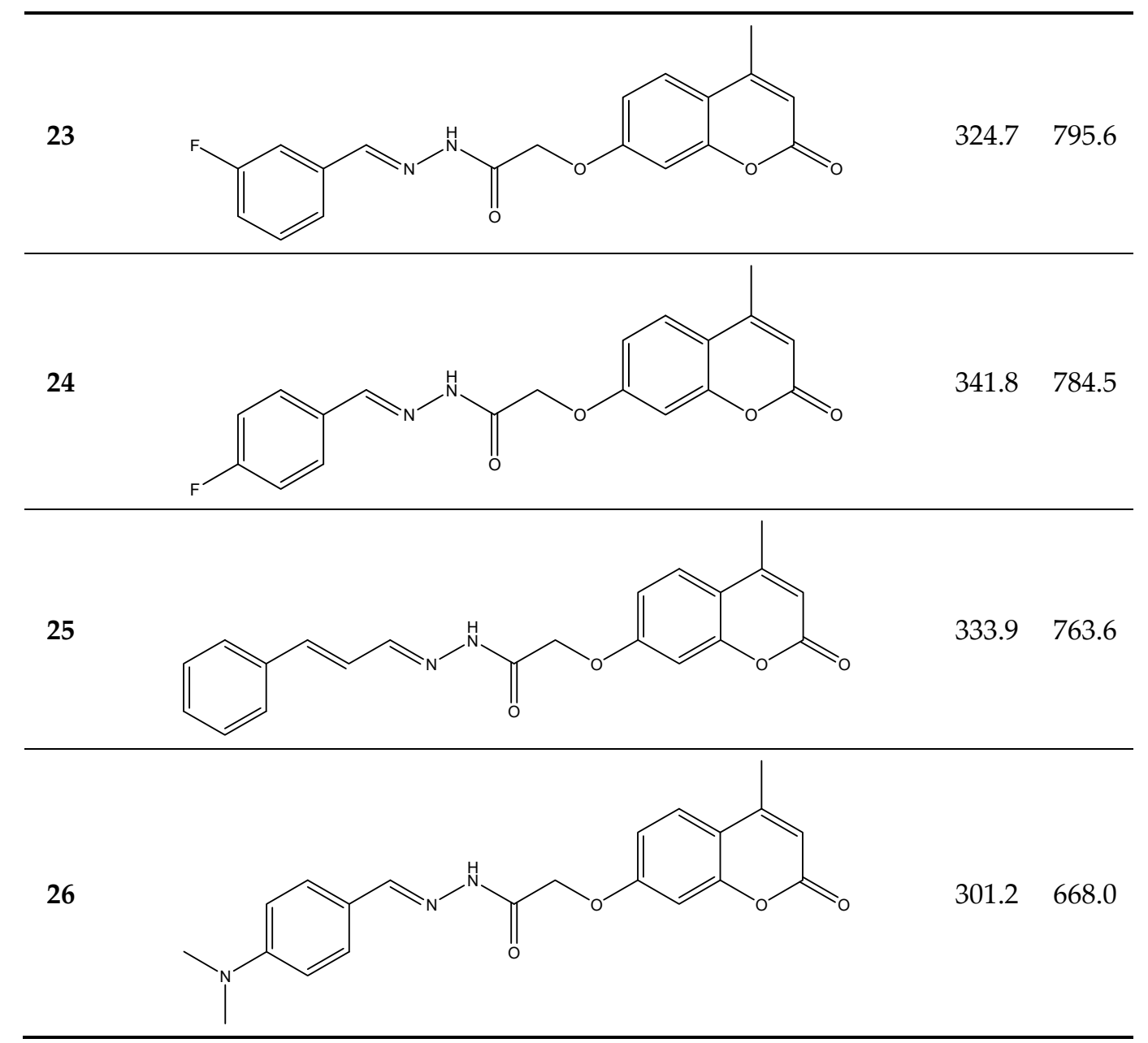

Table 2. Structures of studied thiosemicarbazides and 4-thiazolidinones (compounds 27-36) and results of thermodynamic calculations $(\mathrm{kcal} / \mathrm{mol})$.

No.




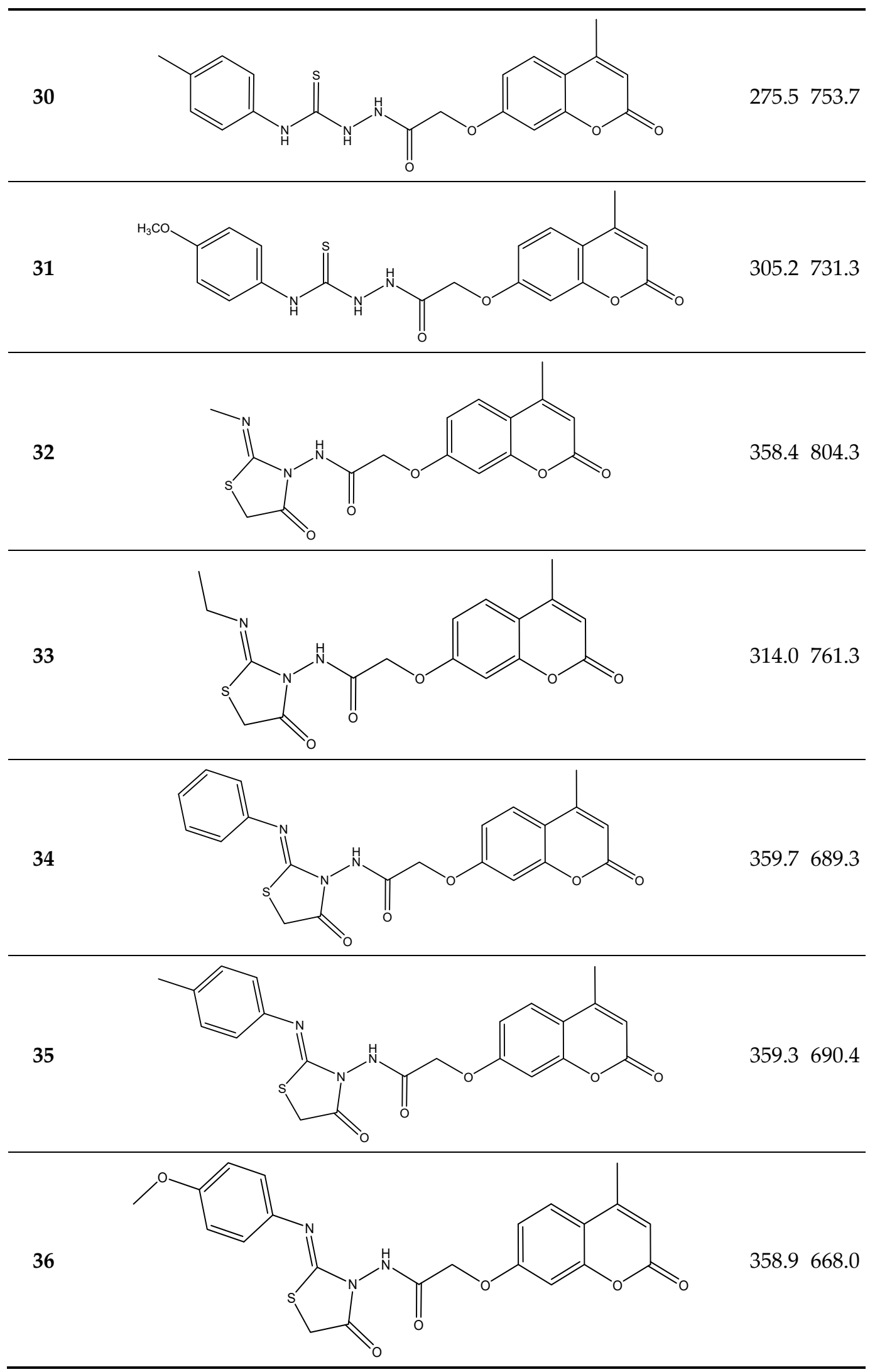


Table 3. Structures of studied oxadiazoles (compounds 37-51) and results of thermodynamic calculations (kcal/mol).

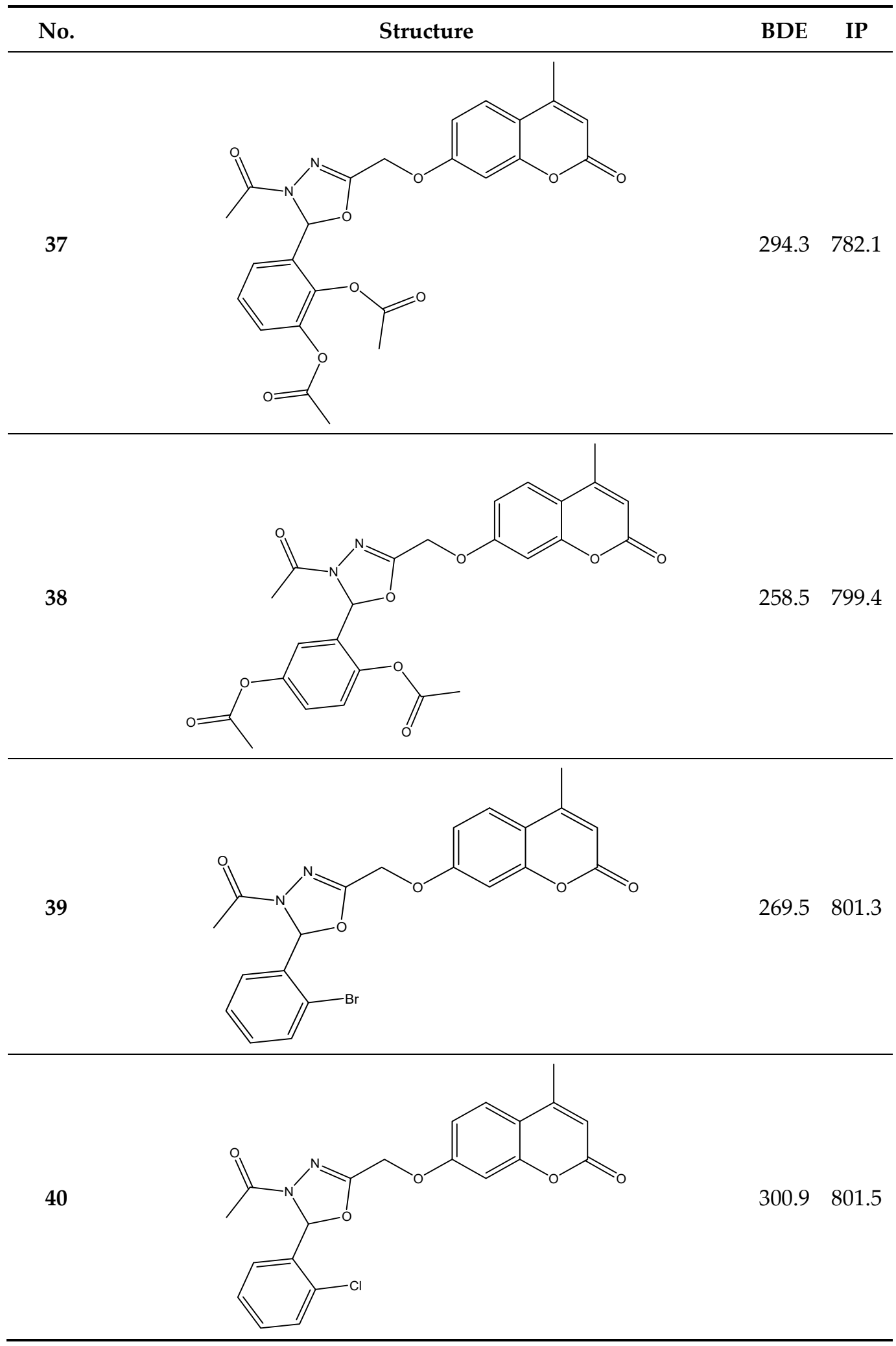




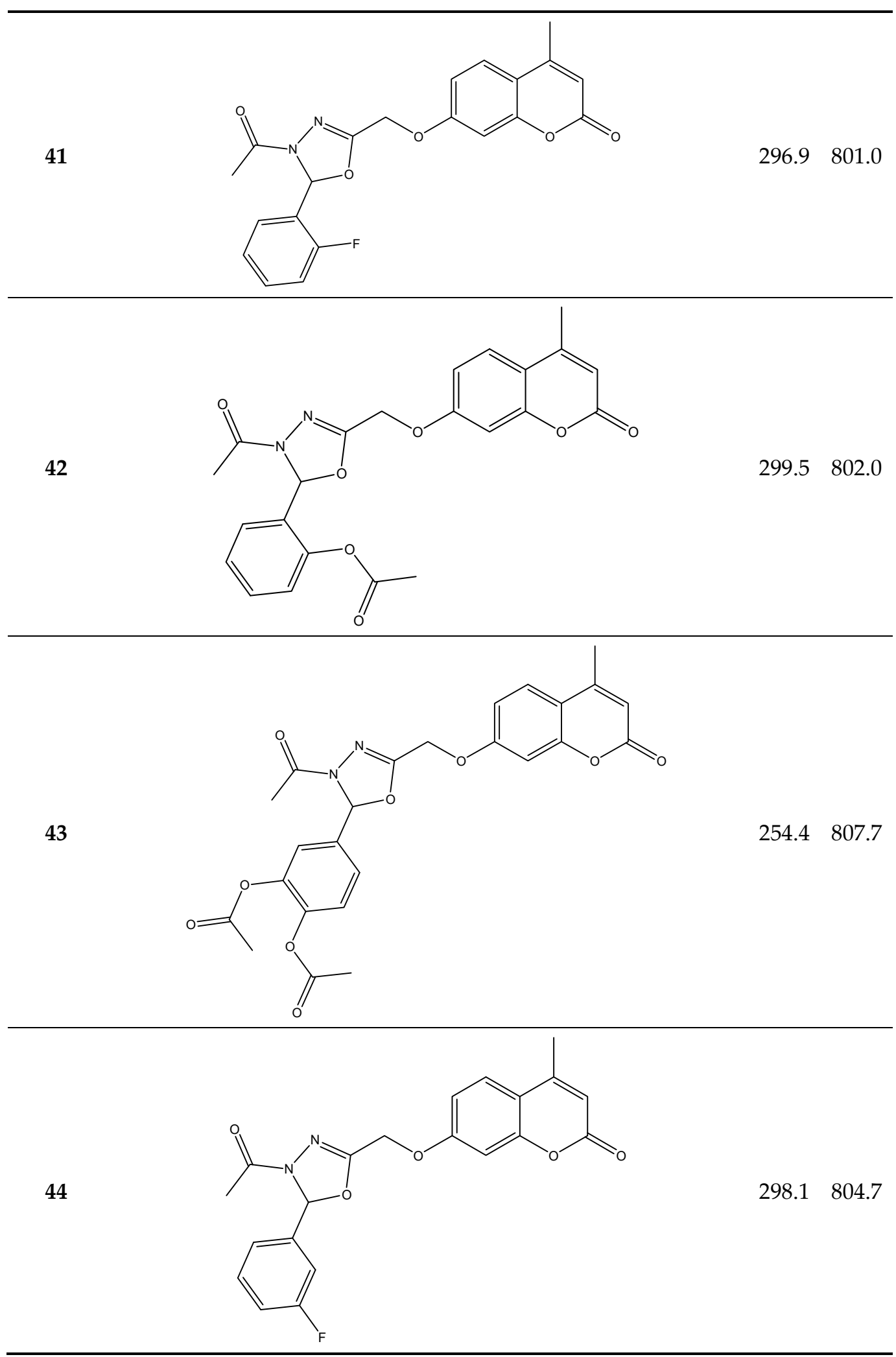




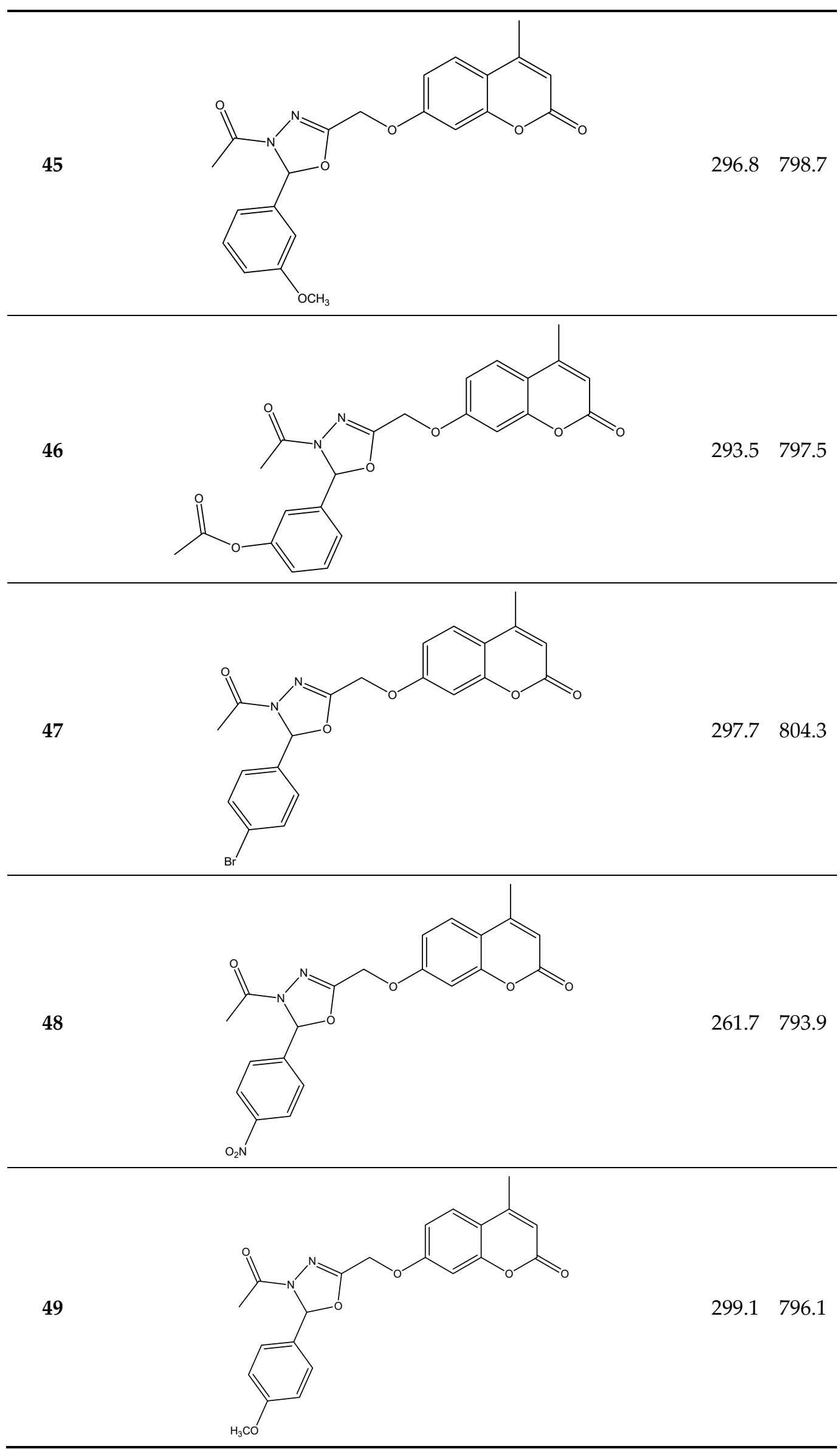




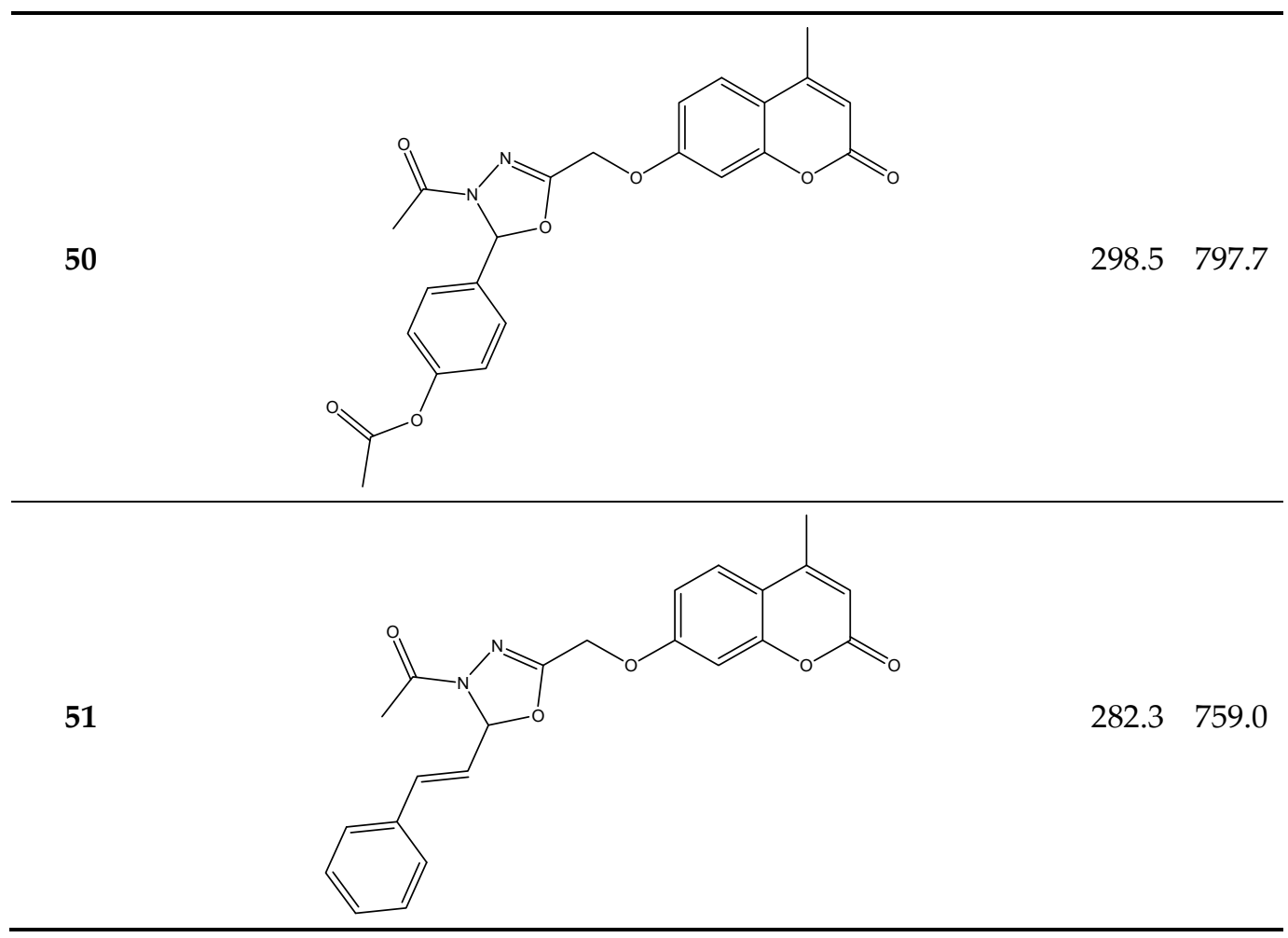

Table 4 gives an overview of the number of $\mathrm{OH}-$ and $\mathrm{NH}-$ groups and the number of vicinal $\mathrm{OH}$ - groups in the structure of studied compounds.

Table 4. Summary of main studied structural characteristics of analyzed compounds.

\begin{tabular}{cccc}
\hline Compound & n-OH & n-Vicinal OH & n-NH \\
\hline $\mathbf{1}$ & 0 & 0 & 1 \\
$\mathbf{2}$ & 1 & 0 & 1 \\
$\mathbf{3}$ & 1 & 0 & 1 \\
$\mathbf{4}$ & 1 & 0 & 1 \\
$\mathbf{5}$ & 0 & 0 & 1 \\
$\mathbf{6}$ & 0 & 0 & 1 \\
$\mathbf{7}$ & 0 & 0 & 1 \\
$\mathbf{8}$ & 2 & 1 & 1 \\
$\mathbf{9}$ & 2 & 0 & 1 \\
$\mathbf{1 0}$ & 2 & 0 & 1 \\
$\mathbf{1 1}$ & 2 & 1 & 1 \\
$\mathbf{1 2}$ & 2 & 0 & 1 \\
$\mathbf{1 3}$ & 2 & 0 & 1 \\
$\mathbf{1 4}$ & 1 & 0 & 1 \\
$\mathbf{1 5}$ & 0 & 0 & 1 \\
$\mathbf{1 6}$ & 1 & 0 & 1 \\
$\mathbf{1 7}$ & 0 & 0 & 1 \\
$\mathbf{1 8}$ & 0 & 0 & 1 \\
$\mathbf{1 9}$ & 0 & 0 & 1 \\
$\mathbf{2 0}$ & 0 & 0 & 1 \\
$\mathbf{2 1}$ & 0 & 0 & 1 \\
$\mathbf{2 2}$ & 0 & 0 & 1 \\
$\mathbf{2 3}$ & 0 & 0 & 1 \\
$\mathbf{2 4}$ & 0 & 0 & 1
\end{tabular}




$\begin{array}{llll}25 & 0 & 0 & 1 \\ 26 & 0 & 0 & 1 \\ 27 & 0 & 0 & 3 \\ 28 & 0 & 0 & 3 \\ 29 & 0 & 0 & 3 \\ 30 & 0 & 0 & 3 \\ 31 & 0 & 0 & 3 \\ 32 & 0 & 0 & 1 \\ 33 & 0 & 0 & 1 \\ 34 & 0 & 0 & 1 \\ 35 & 0 & 0 & 1 \\ 36 & 0 & 0 & 1 \\ 37 & 0 & 0 & 0 \\ 38 & 0 & 0 & 0 \\ 39 & 0 & 0 & 0 \\ 40 & 0 & 0 & 0 \\ 41 & 0 & 0 & 0 \\ 42 & 0 & 0 & 0 \\ 43 & 0 & 0 & 0 \\ 44 & 0 & 0 & 0 \\ 45 & 0 & 0 & 0 \\ 46 & 0 & 0 & 0 \\ 47 & 0 & 0 & 0 \\ 48 & 0 & 0 & 0 \\ 49 & 0 & 0 & 0 \\ \mathbf{5 0} & 0 & 0 & 0 \\ \mathbf{5 1} & 0 & & \end{array}$

Table 5 gives a comparison of thermodynamic parameters for compounds that have $\mathrm{OH}-$ and $\mathrm{NH}$ - groups (Schiff bases, compounds 2-4, 8-13, and 15).

Table 5. Comparison of bond dissociation enthalpy (BDE) values for compounds containing $\mathrm{OH}-$ and $\mathrm{NH}$ - group.

\begin{tabular}{ccc}
\hline Compound & N-H BDE & O-H BDE \\
\hline $\mathbf{2}$ & 457.5 & 375.5 \\
$\mathbf{3}$ & 336.6 & 342.8 \\
$\mathbf{4}$ & 347.0 & 334.5 \\
$\mathbf{8}$ & 379.7 & 335.8 \\
$\mathbf{9}$ & 321.3 & 319.4 \\
$\mathbf{1 0}$ & 322.3 & 299.1 \\
$\mathbf{1 1}$ & 336.6 & 316.9 \\
$\mathbf{1 2}$ & 315.3 & 332.6 \\
$\mathbf{1 3}$ & 335.8 & 319.6 \\
$\mathbf{1 5}$ & 352.9 & 394.7 \\
\hline
\end{tabular}

As can be seen in Table 4, some studied compounds have only one OH- group (2-14, 13, 15), some have two (8-12), and some have vicinal $\mathrm{OH}-$ groups (8 and 11). All these compounds are Schiff bases and all show better results of thermodynamic calculations. Some compounds contain one (1-26, 32-36) or more (27-31) NH- groups, but calculated $\mathrm{BDE}$ and IP values for these compounds were not better compared to the ones obtained 
for Schiff bases. Some compounds contain $\mathrm{OH}-$ and $\mathrm{NH}$ - group (Tables 4 and 5, compounds $\mathbf{2}-\mathbf{4}, \mathbf{8 - 1 3}$, and 15). These compounds are Schiff bases, and as can be seen from Table 5, the BDE of the $\mathrm{O}-\mathrm{H}$ bond is slightly more favorable compared to the BDE of N$\mathrm{H}$ bond cleavage. Compounds 37-51 (oxadiazoles) do not have $\mathrm{OH}-$ or $\mathrm{NH}-$ group, hence for these compounds BDE and IP values for the $\mathrm{C}-\mathrm{H}$ bond were calculated. Obtained results do not show better antioxidant potential for oxadiazoles, but they are not "much worse" antioxidants than compounds with $\mathrm{OH}-$ and $\mathrm{NH}-$ groups.

BDE values for Schiff bases were determined to be in the range $285.5-373.5 \mathrm{kcal} / \mathrm{mol}$, BDE values for thiosemicarbazides and 4-thiazolidinones were in the range 275.5-358.9 $\mathrm{kcal} / \mathrm{mol}$, and for oxadiazoles in the range of $258.5-300.9 \mathrm{kcal} / \mathrm{mol}$. All obtained results are almost twice higher than results obtained by Mohajeri et al. (2009). These results indicate studied compounds as weaker antioxidants. Their inefficiency may be due to the fact that studied thiosemicarbazides, 4-thiazolidinones and oxadiazoles do not possess $\mathrm{OH}-$ group, while five Schiff bases have $\mathrm{OH}$ - group, five have two $\mathrm{OH}$ - groups, and only two have vicinal $\mathrm{OH}$ - groups.

Our study determined the following IP values: $684.5-852.2 \mathrm{kcal} / \mathrm{mol}$ for Schiff bases, $668.0-804.3 \mathrm{kcal} / \mathrm{mol}$ for thiosemicarbazides and 4-thiazolidinones, and 782.1-807.7 $\mathrm{kcal} / \mathrm{mol}$ for oxadiazoles. These results are in some cases almost four times higher than results obtained by Mohajeri et al. (2009) and clearly indicate the lower antioxidant activity of studied compounds [15]. Overview of scientific literature related to the experimental determination of antioxidant activity (DPPH assay) [16-21] also indicates this group of compounds as not significant antioxidants and relates observed antioxidant activity with the number of $\mathrm{OH}$ - groups.

\section{Conclusions}

Coumarins are heterocyclic compounds widely used in medicinal chemistry and drug development, due to their anticancer, antibacterial and anti-inflammatory activity. Some of these compounds have a very powerful antioxidant activity that makes them useful in the removal of reactive oxygen species and minimizing of oxidative damage of biological macromolecules. In this preliminary study, MOPAC and PM7 were implemented in order to determine thermodynamic parameters BDE and IP for heterocyclic compounds containing coumarin core (Schiff bases, thiosemicarbazides, oxadiazoles and 4-thiazolidinones). Two mechanisms of antioxidant activity were studied, HAT and SET-PT. They are competitive mechanisms, with HAT being preferred in non-polar medium and SETPT in the polar medium. Calculations were done in the gas phase, for which the preferred mechanism is HAT. Thermodynamics of $\mathrm{O}-\mathrm{H}, \mathrm{C}-\mathrm{H}$ and $\mathrm{N}-\mathrm{H}$ bond cleavage were studied, as well as the effect of number and position of $\mathrm{OH}-$ and other functional groups (if there are any) on antioxidant activity. Obtained results indicate a very unfavorable BDE value and at least twice as big IP value of studied compounds. Results thus indicate that these compounds do not exhibit a very high antioxidant activity, which is probably due to the lack of structural motifs characteristic for superior antioxidant activity, such as $\mathrm{OH}-$ groups. It could also be concluded that antioxidant activity probably does not occur via studied mechanisms. Hence, in order to determine the operative mechanism of antioxidant activity of these compounds, additional research is necessary, which would focus on other locations of antioxidant activity and other mechanisms by implementing other computational program packages.

Funding: This research received no external funding.

Institutional Review Board Statement: Not applicable.

Informed Consent Statement: Not applicable.

Data Availability Statement: Data available in a publicly accessible repository. Data available on request due to restrictions eg privacy or ethical. 
Conflicts of Interest: The authors declare no conflict of interest.

\section{References}

1. Jain, P.K.; Joshi, H. Coumarin: Chemical and pharmacological profile. J. Appl. Pharm. Sci. 2012, 2, $236-240$.

2. Bruneton, J. Pharmagognosy, Pyhtochemistry, Medical Plants, 2nd ed.; Intercept: Hampshire, UK, 1999.

3. Matilla, P.; Hellström, J.; Törrönen, R. Phenolic acids in berries, fruits, and beverages. J. Agric. Food Chem. 2006, 54, 7193-7199.

4. Wildman, R.E. Handbook of Nutraceuticals and Functional Foods, 2nd ed.; CRC Press: Boca Raton, FL, USA, 2016.

5. Aslam, K.K.; Khosa, M.K.; Jahan, N.; Nosheen, S. Short communication: Synthesis and applications of Coumarin. Pak. J. Pharm. Sci. 2010, 23, 449-454.

6. Abraham, K.; Wöhrlich, F.; Lindtner, O.; Heinemeyer, G.; Lampen, A. Toxicology and risk assessment of coumarin: Focus on human data. Mol. Nutr. Food Res. 2010, 54, 228-239.

7. Liu, B.; Raeth, T.; Beuerle, T.; Beerhues, L. A novel 4-hydroxycoumarin biosynthetic pathway. Plant Mol. Biol. $2010,72,17-25$.

8. Matos, M.J.; Santana, L.; Uriarte, E.; Abreu, O.A.; Molina, E.; Yordi, E.G. Coumarins-An Important Class of Phytochemicals. In Isolation, Characterisation and Role in Human Health, 1st ed.; Rao, V., Rao, L., Eds.; IntechOpen: London, UK, 2015; pp. 113-140.

9. Lake, B.G. Coumarin metabolism, toxicity and carcinogenicity: Relevance for human risk assessment. Food. Chem. Toxicol. 1999, $37,423-453$.

10. Gamulin, S.; Kovač, Z.; Marušić, M. Patofiziologija, 7th ed.; Medicinska naklada: Zagreb, Croatia, 2011.

11. Jeremić, S.; Amić, A.; Stanojević-Pirković, M.; Marković, Z. Selected anthraquinones as potential free radical scavengers and Pglycoprotein inhibitors. Org. Biomol. Chem. 2018, 16, 1890-1902.

12. Prior, R.L.; Wu, X.; Schaich, K. Standardized methods for the determination of antioxidant capacity and phenolics in foods and dietary supplements. J. Agric. Food Chem. 2005, 53, 4290-4302.

13. Marković, Z. Study of the mechanisms of antioxidative action of different antioxidants. J. Serb. Soc. Comput. Mech. 2016, 10, 135150.

14. Dimić, D.S. Eksperimentalno i Teorijsko Ispitivanje Odnosa Struktura-Antiradikalska Aktivnost Odabranih Neurotransmitera, Njihovih Prekursora i Metabolita. Ph.D. Thesis, Sveučilište u Beogradu, Fakultet za fizikalnu kemiju, Beograd, Serbia, 2018.

15. Mohajer, A.; Somayeh Asemani, S. Theoretical investigation on antioxidant activity of vitamins and phenolic acids for designing a novel antioxidant. J. Mol. Struct. 2009, 930, 15-20.

16. Čačić, M.; Molnar, M. Design, Synthesis and Characterization of Some Novel 3-Coumarinyl-5-aryliden-1,3-thiazolidine-2,4-diones and Their Antioxidant Activity. Z. Naturforsch. 2011, 66, 177-183.

17. Čačić, M.; Molnar, M.; Šarkanj, B.; Has-Schon, E.; Rajković, V. Synthesis and antioxidant activity of some new coumarinyl-1, 3thiazolidine-4-ones. Molecules 2010, 15, 6795-6809.

18. Čačić, M.; Molnar, M.; Strelec, I. Synthesis and biological evaluation of a novel series of 1, 3-dicoumarinyl-5-aryl-2-pyrazolines. Heterocycles 2011, 83, 1553-1566.

19. Šarkanj, B.; Čačić, M.; Molnar, M.; Grille, L. 4-Methyl-7-hydroxycoumarin antifungal and antioxidant activity enhancement by substitution with thiosemicarbazide and thiazolidinone moieties. Food Chem. 2013, 139, 488-495.

20. Al-Amiery, A.A.; Al-Majedy, Y.K.; Kadhum, A.A.H.; Mohamad, A.B. Hydrogen Peroxide Scavenging Activity of Novel Coumarins Synthesized Using Different Approaches. PLoS ONE 2015, 10, e0132175.

21. Molnar, M.; Amić, A.; Pavić, V.; Kovač, T.; Kovač, M.; Has-Schon, E. Biological study on novel coumarinyl 1, 3, 4-oxadiazoles. Turk. J. Chem. 2018, 42, 146-157. 